\title{
Reality Training of Volleyball with Upper Levels at the Provinces of Gaza and its Relationship to the Level of Achievement Skills.
}

\author{
Mohamed Houcine Ibrahim Alajjouri \\ University of Al-Aqsa, Gaza, Palestine.
}

\begin{abstract}
The concept of management training did not start today. The Greeks prepared the ancient Olympic Games exercising, and practicing in advance. The phenomenon of training is an action that is designed to prepare individuals for a certain exercises with proper diet. This study aimed to identify the reality training of Volley ball for the upper levels in provinces of Gaza and its relationship to the level of achievement skills of the players, and access to the results the researcher used the instrument resolution to recognize the reality of training which included the training process.
\end{abstract}

Keywords: Reality of Training - Skills Achievement - Volleyball - Gaza.

\section{Introduction}

Volleyball is one of the most difficult kinds of sport, which is conditioned by unpredictability of the opponent's physical actions character; by the necessity to model constantly own behavior on the ground in suddenly appearing game situations, the indices improvement of speed of reaction to exogenous and inner irritants, the skills of techniques extrapolation development depending on the conditions of their fulfilment. Shneyder, (2015), mention that nowadays the methodology of training is oriented at qualified sportsmen and a long-term period of sports training, moreover, the technique of special physical actions is mastered by means of cut-and-test method.

According to Spirin,(2007), Sidash,(2012), and Pustoshilo,(2010), the effectiveness of competitive activity of volleyball players is conditioned by their ability to fulfil effective defensive actions. One of the most important and widely-spread kinds of defence is blocking, which determined tall players involvement (Nazarenko, 2003; Pustoshilo, 2010; Kuznetsova, 2011).In order to break the block a definite development level of the specific for volleyball motional coordinating qualities is demanded: muscular power, speed of motor acts fulfilment, accuracy of movements, spring ability, dexterity, which provide physical and technical readiness improvement of attackers. This conditions the necessity to increase the effectiveness of the defensive actions of volleyball players (Goncharova, 2007; Avramova, 2012; Burtsev, 2011; Ezhi, 2007; Burtsev, 2011; Kolesnik, 2012). Hence the need for research in the relevant field to face the volleyball in the Gaza Provinces from delays noticeable compared to the world level, or even Arab, where the researcher felt that there is a real problem in the training process and the requirements of the different elements, whether in the preparation of qualified trainer, or the circumstances surrounding the possibilities on Gaza Provinces and the political situation, including closures and psychological pressure and in stability, The researcher believes that such a fact, the training may hamper the achievement level skills, especially in competitions, hence it launched the idea of seeking the current attempt by the researcher in the coach development and those in charge of sport Palestinian volleyball in the form of true reality to find out the main reasons for the low skill level, especially after the low-results of the Palestinian team in the recent Arab session organized by Qatar. This study aimed to identify the reality training of Volley ball for the upper levels in provinces of Gaza and its relationship to the level of achievement skills of the players, and access to the results the researcher used the instrument resolution to recognize the reality of training, which included the training process.

\section{1-Participants:}

\section{Methods.}

Our population is made up of the volleyball players the upper levels in Gaza provinces. The study sample was divided into two parts as follows: Section I: "Those who have applied to identify the reality of training" (28) volley ball players: selected purposively by two players from each club of the Federation of Volleyball and who have been nominated by their clubs to participate in the training of trainers session hosted by the International Federation of volleyball in Gaza from 15 to 26 March 2012.

Section II: "Those who applied the skills tests" (24) Volleyball players of the upper levels randomly chosen by the organization of the players who participated in the General League Championship for the year 2011. 


\section{2-Measurements:}

\section{Description of the questionnaire:}

Our questionnaire is composed of 57 items distributed over 5 dimensions.

* The first dimension: reality of the training situation (14 items).

* The second dimension: political situation of the Gaza provinces ( 7 items).

* The third dimension: the possibilities available for the training of volleyball (12 items).

* The fourth dimension: the club signed (10 items).

* The fifth dimension: the reality of the Palestinian Federation of volleyball (14 items).

We have showed the questionnaire to a group of (3) experts with doctorate in sports training and sports psychology degree, to express their opinion in both the resolution and its expression axes. After the insertion of the proposed amendments by the arbitrators, we have printed the final version of the questionnaire.

\section{The stability of the questionnaire:}

\section{Results and Discussions.}

The questionnaire was given to a random sample of (6) members of the volleyball players at the upper levels of the Gaza Strip in order to ensure its stability, where re-applied, were reliability coefficient calculating way retail mid-term and internal consistency by Alpha of Cronbach equation areas separate tool as a whole, since the value of constancy of the instrument as a whole (0.771) and was considered the appropriate intercourses for the purposes of this research, the following table shows the details.

Tab. 1- Reliability coefficient retail midterm Alpha Cronbach axes questionnaire and paragraphs.

\begin{tabular}{|l|c|c|c|c|c|c|c|}
\hline \multirow{2}{*}{ Axes } & \multirow{2}{*}{$\begin{array}{l}\text { Number of } \\
\text { paragraphs }\end{array}$} & \multicolumn{2}{|c|}{ Individual paragraphs } & \multicolumn{2}{c|}{ Marital paragraphs } & \multirow{2}{*}{ Link midterm retail } & \multirow{2}{*}{ Cronbach Alpha } \\
\cline { 3 - 6 } & & Means & Sd & Means & Sd & & \\
\hline \hline Training & 14 & 4.41 & 2.82 & 4.18 & 3.05 & 0.693 & $\mathbf{0 . 7 1 1}$ \\
\hline Possibilities & 11 & 8.66 & 3.39 & 8.79 & 3.32 & 0.754 & $\mathbf{0 . 8 1 3}$ \\
\hline Clubs & 10 & 9.96 & 3.89 & 9.72 & 4.11 & 0.754 & $\mathbf{0 . 7 4 9}$ \\
\hline Union & 14 & 13.01 & 4.13 & 12.92 & 4.32 & 0.712 & $\mathbf{0 . 7 8 9}$ \\
\hline Political Status & $\mathbf{7}$ & 13.26 & 4.20 & 13.57 & 4.51 & $\mathbf{0 . 8 1 9}$ & $\mathbf{0 . 7 9 1}$ \\
\hline \multicolumn{1}{c}{ Total } & $\mathbf{5 7}$ & $\mathbf{4 9 . 3}$ & $\mathbf{1 8 . 4 3}$ & $\mathbf{4 9 . 1 8}$ & $\mathbf{1 9 . 3 1}$ & $\mathbf{0 . 7 3 3}$ & $\mathbf{0 . 7 7 1}$ \\
\hline
\end{tabular}

To make sure the reliability of study tool, the researcher to apply and re-apply the instrument to 11 player, the internal consistency by Cronbach's alpha areas and tool whole equation, is evident from Table 1 that the mid-term retail reliability coefficient for axes resolution and paragraphs ranged between $(0.686-0.819)$ and the total amounted to paragraphs (.733), and corrects alpha Cronbach ranged between $(0.711-0.813)$ of the axes and the total paragraphs $(0.771)$ which shows the stability of the questionnaire and then considered the appropriate ratios for the purposes of this research.

\section{Reality of training volleyball in the upper levels of the Gaza Provinces.}

To limit the reality of training volleyball in the upper levels of the Gaza provinces through all averages, percentages and standard deviations for each positive and negative paragraph in one table as follows:

Tab.2- Averages, percentages and standard deviations for all axes.

\begin{tabular}{|c|c|c|c|c|c|c|}
\hline axis & $\begin{array}{c}\text { Average account positive } \\
\text { paragraphs }\end{array}$ & $\begin{array}{l}\text { The percentage of } \\
\text { positive vertebrae }\end{array}$ & $\begin{array}{l}\text { Average account } \\
\text { paragraphs negative }\end{array}$ & $\begin{array}{c}\text { The percentage of } \\
\text { negative paragraphs }\end{array}$ & $\begin{array}{l}\text { The total proportion of } \\
\text { Ithe axis after inverting of } \\
\text { the negative grades }\end{array}$ & Standard Deviation \\
\hline Training & 2.11 & $42.2 \%$ & 3.1 & $61.2 \%$ & $40.5 \%$ & 0.89 \\
\hline Possibilities & 2.29 & $45.9 \%$ & 3.95 & $79 \%$ & $33.5 \%$ & 1.03 \\
\hline Club & 2.28 & $45.5 \%$ & - & - & $45.5 \%$ & 0.79 \\
\hline Union & 2.15 & $42.9 \%$ & - & - & $42.9 \%$ & 0.66 \\
\hline Political status & - & - & 3.2 & $64.3 \%$ & $35.7 \%$ & 0.75 \\
\hline$\overline{\text { Total }}$ & 2.21 & $44.13 \%$ & 3.42 & $68.2 \%$ & $39.6 \%$ & 0.82 \\
\hline
\end{tabular}


By the table (2), we illustrated that the average of all the positive paragraphs in identifying "the reality of training volleyball Higher levels of the Gaza Strip" and all axes were (2.21) and a percentage of 44.13\%, and if the inverting of the ladder stairs to shed light on the remaining half of the positive clauses; the ratio becomes $55.87 \%$ negative .It is also clear from the table (2) that the average of negative paragraphs was (3.42) and a percentage of $68.2 \%$,It could be argued that the addition of grades "inverted" for the positive paragraphs on the negative paragraphs gives us the reality of negative training by $62 \%$,This means the reality of positive train by only $38 \%$, Which gives an indication of the low level of the elements of the natural training for the volleyball sport in the Gaza Strip, and this shows that a healthy environment for volleyball training in the Higher levels of the Gaza Strip is classified as a " Unsound training environment," so the researcher attributed the reasons for this decline to what is stated in commenting on the results of each question of the five questions above study, the researcher has used the following form chart to illustrate the percentages of the reality of training.

\section{The level of achievement of gifted volleyball players in the upper levels in the provinces of Gaza.}

To answer the question about the level of achievement of gifted volleyball players in the upper levels in the provinces of Gaza, we have used an appropriate statistical operation and reached the following results.

Tab.3- Shows the correlation coefficient and arranging the level of achievement skills of volleyball players in the upper level in Gaza.

\begin{tabular}{|c|c|c|c|c|c|c|}
\hline Series & Level skill achievement & $\begin{array}{l}\text { Average account from } \\
(10)\end{array}$ & $\begin{array}{l}\text { Standard } \\
\text { Deviation }\end{array}$ & $\begin{array}{c}\text { Order of the level of } \\
\text { achievement }\end{array}$ & $\begin{array}{l}\text { Degree of } \\
\text { correlation }\end{array}$ & Class spread sheet \\
\hline 1 & $\begin{array}{l}\text { Transmission of the top } \\
\text { and bottom }\end{array}$ & 7.6 & 0.896 & 3 & \multirow{5}{*}{0.77} & \multirow{5}{*}{0.27} \\
\hline 2 & $\begin{array}{l}\text { The reception from the } \\
\text { bottom arms }\end{array}$ & 8.46 & 1.131 & 2 & & \\
\hline 3 & $\begin{array}{l}\text { Scrolling from the top of } \\
\text { the "preparation }\end{array}$ & 8.73 & 0.764 & 1 & & \\
\hline \multirow{2}{*}{4} & \multirow{2}{*}{ Batting over whelming } & $\overline{6.4}$ & 0.579 & 5 & & \\
\hline & & 6.88 & 0.594 & 4 & & \\
\hline
\end{tabular}

By the table (3) we illustrated a correlation between the level of achievement skills for volleyball players in the upper levels, also the results indicated that the correlation coefficient is equal to (0.77), a value greater than Tabulated value of $(0.27)$ at the level of which confirms the strength of the relationship. Despite the presence of correlation between the skills they have been mixed to a low degree, was the first slider of the highest order and a mean skill (8.73) followed respectively (scroll down, the transmission of the top and bottom, bulwark, batting overwhelming).

4. The details of crude grades and standardized and the level of skill achievement.

Tab.4- shows the details of crude grades and standardized and the level of skill achievement.

\begin{tabular}{|c|l|c|c|c|c|c|}
\hline Series & \multicolumn{1}{|c|}{ Skills } & $\begin{array}{c}\text { Raw scores for each } \\
\text { players }\end{array}$ & $\begin{array}{c}\text { Average crude grades } \\
\mathbf{n = 2 4}\end{array}$ & $\begin{array}{c}\text { Grading standard } \\
\text { from(10) }\end{array}$ & Percentage & Level \\
\hline \hline 1 & $\begin{array}{l}\text { Transmission of the top } \\
\text { and bottom }\end{array}$ & 912 to 1200 & 38 to 50 & 7.6 & $76 \%$ & Medium \\
\hline 2 & $\begin{array}{l}\text { The reception from the } \\
\text { bottom arms }\end{array}$ & 609 to 720 & 25,38 to 30 & 8.46 & $84.58 \%$ & Good \\
\hline 3 & $\begin{array}{l}\text { Scrolling from the top of } \\
\text { the "preparation }\end{array}$ & 2095 to 2400 & 87.3 to 100 & 8.73 & $87.3 \%$ & Good \\
\hline 4 & battingoverwhelming & 384 to 600 & 16 to 25 & 6.4 & $64 \%$ & $\begin{array}{c}\text { Lower than the } \\
\text { average }\end{array}$ \\
\hline 5 & Bulwark & 743 to 1080 & 30.95 to 45 & 6.88 & $68.8 \%$ & $\begin{array}{c}\text { Lower than the } \\
\text { average }\end{array}$ \\
\hline
\end{tabular}

Evident from the table (4) that the level of achievement skills for the volleyball players in the upper levels of the Gaza Strip is (average) and the percentage is (76.14\%) and the researcher believes that this level does not represent the required the higher levels for volleyball teams, and it is not equivalent to the external levels, whether at the universal level 1 or even Arab. 


\section{Relationship at the level of significance ( $\square \square$ 0.05) between th reality of training volleyball in the higher levels of achievement and the level of skill of the players.}

To answer the seventh question which is "Is there a statistically significant relationship at the level of significance $(\alpha \geq 0.05)$ between the reality of training volleyball in the higher levels of achievement and the level of skill of the players?" we have used the appropriate statistical operations and reached the following results:

Tab.5- The relationship between the reality of training volleyball in the higher levels of and the level of skill achievement of the players.

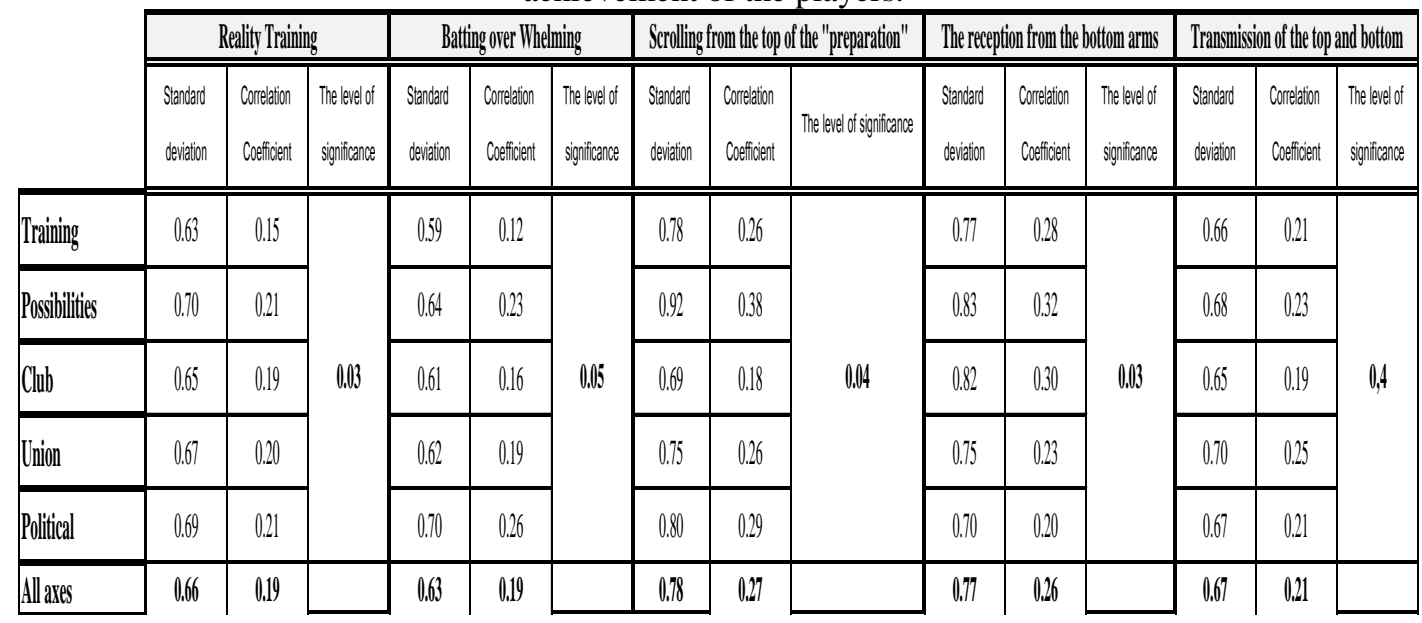

We have illustrated by the results of table (5) that the correlation coefficients showing the relationship "between the reality of training volleyball in the upper levels and the level of achievement, the technically gifted players" were ranging between $(0.27$ - 0.19) was recorded (scroll up) the highest correlation to the level of achievement skills of the players and that with correlation coefficient (0.27) and a standard deviation (0.78), Followed by (scroll down) by a factor of correlation (0.26) and a standard deviation (0.77), while the lowest correlation coefficient was (beating overwhelming) of (0.19) and a standard deviation (0.62), as well as (bulwark) worth of correlation (0.19) and a standard deviation (0.66).

The significance level ranged between $(0.05-0.03)$. This indicates the presence of a statistically significant relationship at the level of $(\alpha \geq 0.05)$ between the reality of training and the level of achievement skills for volleyball players in the upper levels of the Gaza Strip, which means that the reality of poor training in the Gaza Strip and revealed by the current research in the first five questions the results, it led to the level of achievement of average Skill for volleyball players in the upper levels revealed by the results of the sixth question.

\section{Conclusion}

In the light of the objective of the research and its questions, and depending on inhalers tool and method of statistical analysis of scientific practice, and through the presentation of the results and interpretation, we have extracted the following conclusions:

1. Reality of Training Volleyball in the upper levels of the Gaza Strip is «negative" and does not represent a sound training environment.

2. Achievement skills for the volleyball players in the upper levels of the Gaza Strip "average".

3. There is a strong correlation between the reality of negative training of volleyball in the upper levels of the Gaza Strip and the average skill level of achievement.

\section{References}

[1]. Avramova, N.V. (2012). Tests and evaluation criteria of motional actions programming skills of 15- 17 year old female volleyball players / N.V. Avramova, L.D. Nazarenko // Pedagogical-psychological and medical-biological problems of physical culture and sport. № 2(23). P.10- 16.Access mode: http://kamgifk.ru/sites/default/files/magazine/avramova.

[2]. Burtsev, A.V. (2011). Spatio-temporal orientation development among qualified volleyball players / A.V. Burtsev // Pedagogicalpsychological and medical-biological problems of physical culture and sport. №1. P. 34-38. - Access mode: http://www/kamgifk.chelny. Net/journal.

[3]. Goncharova, A.V.(2007). Reliability increase of female volleyball players' defensive actions taking into consideration sports motional objectives solution / A. V. Goncharova// Theory and practice of physical culture. №12. P. 45-48.

[4]. Ezhi N. (2007). Training simulators use in conditional and technical training of volleyball players /Novik Ezhi // Theory and practice of physical culture. №12. P. 42-44. 
[5]. Kolesnik, I.S. (2012). Spatio-temporal orientation formation among volleyball players on the basis of motional actions extrapolation manual / I.S. Kolesnik, A.V. Burtsev. - Ulyanovsk. 157 p.

[6]. Kuznetsova, Z. M. (2011). The program realization of students' personal qualities formation in educational activity as one of real preconditions for the content renewal of the specialists training in the system of higher education (by the example of students from Povolzhskaya State Academy of Physical Culture, Sport and Tourism in the specialty "Service and tourism") / Z.M. Kuznetsova // Pedagogical-psychological and medical-biological problems of physical culture and sport. №1 (18). P. 143-149.

[7]. Nazarenko, L.D. (2003). Means and methods of motional coordinations development / L.D. Nazarenko. Moscow: Theory and practice of physical culture, 2003. $258 \mathrm{p}$.

[8]. Spirin, M.P. (2007). Competitive activity of volleyball players at a modern stage of game development /M.P. Spirin, G.Y. Shipulin, O.E. Serdykova, L.V. Zhilina, O.V.Chernykh //Theory and practice of physical culture.- №9. P. 34-37.

[9]. Sidash, A.L. (2012). Local poundage use for the accuracy improvement of the upper serving among volleyball players / A. L. Sidash//Theory and practice of physical culture. №1. P. 79-82.

[10]. Pustoshilo, P.V. (2010). Psycho-physiological aspects of students-volleyball players training during a yearly training cycle / P. V. Pustoshilo// Theory and practice of physical culture. №10. P. 18.

[11]. Shneyder, V.Y. (2015). Psychological conditions for the future trainers' competence development as the organizers of an innovative strategy of teaching volleyball / V. Y. Shneyder, V. Y. Losev//Theory and practice of physical culture. №11. P. 89-93. 